\title{
An Empirical Investigation of the Intuitiveness of Process Landscape Designs
}

\author{
Gregor Polančičl(®) ${ }^{(\otimes a v l o ~ B r i n}{ }^{2}$, Lucineia Heloisa Thom ${ }^{3}$, Encarna Sosa ${ }^{4}$, \\ and Mateja Kocbek Bule ${ }^{1}$ \\ ${ }^{1}$ Faculty of Electrical Engineering and Computer Science, \\ University of Maribor, Koroška cesta 46, 2000 Maribor, Slovenia \\ \{gregor.polancic, mateja.kocbek\} @um.si \\ 2 National Technical University "Kharkiv Polytechnic Institute", \\ 2 Kirpicheva Street, Kharkiv 61002, Ukraine \\ pavelbrin@ukr.net \\ ${ }^{3}$ Federal University of Rio Grande do Sul, Av. Bento Gonçalves, 9500, \\ Porto Alegre, RS 91501-970, Brazil \\ lucineialinf.ufrgs.br \\ ${ }^{4}$ Universidad de Extremadura, Cáceres, Spain \\ esosalunex.es
}

\begin{abstract}
Process landscapes define the scope and relationships between an organization's business processes and are therefore essential for their management. However, in contrast to business process diagrams, where nowadays BPMN prevails, process landscape diagrams lack standardization, which results in numerous process landscape designs. Accordingly, our goal was to investigate how intuitive are current landscape designs to users with low expertise, as well as users having expertise in BPMN and landscape modeling. A total of 302 subjects participated in the research showing that previous expertise impacts the interpretation of landscape elements and designs whereas, in the case of having contextual information, subjects responded more consistently. The results also show that the basic relationships between processes are intuitive to users, also in the case when only proximity between shapes is facilitated. Our findings may imply future designs of languages for process landscapes. They also may be useful for those who actually model process landscape diagrams and search for suitable notations.
\end{abstract}

Keywords: Process landscape $\cdot$ Diagram $\cdot$ Semantic transparency $\cdot$ BPMN

\section{Introduction}

A process landscape diagram represents the top-level part of a process architecture, which stands for "an organized overview of business processes that specifies their relations, which can be accompanied by guidelines that determine how these processes must be organized" [1]. The specification of a process landscape model is the most important challenge for the establishment of a process architecture [2]. For example, a high amount of organizations' services requires an efficient representation of the entire 
process landscape in order to measure the overall organization's potential [3]. A process landscape represents processes as 'black-boxes' and so focuses on interrelationships between processes and external participants. In this manner, a process landscape enables an organization to maintain an overview of processes, which simplifies process-related communication and may represent a starting point for process discovery.

Accordingly, a process landscape model has to be comprehensible by all major stakeholders of an organization [2, 3]. This implies the usage of a common, compact, and intuitive language for the creation of process landscape diagrams. However, no standardized languages for creating process landscapes exist [4], whereas BPMN 2.0 does not cover the wide landscapes and complexities that exist in the process-modeling domain [5, 6]. Consequently, organizations, as well as process modeling tool vendors (e.g., ARIS Express, Visual Paradigm, Vizi Modeler and Signavio), define their own 'overviews of processes' most commonly by imitating 'value chain' diagrams.

As a result, landscape diagrams differ from each other, and while there is no common landscape modeling language, an inexperienced user could infer a different meaning from the appearance of a language element, which could negatively impact the comprehension of a diagram and the corresponding decisions made. And while the graphical representation significantly impacts the cognitive effectiveness of a diagram [7-9], it is important to specify a common palette of comprehensible symbols fitting with the process landscapes domain.

According to these challenges, the main goal of our work was to investigate the intuitiveness of the representations of process landscape designs as found in academia and industry, i.e., to test if representations of landscape concepts are intuitive (i.e. semantically transparent, clear) to people with 'near-to-zero' knowledge of a process landscape design. In this light, we defined the following research questions which could be tested empirically:

- RQ1: Are common landscape designs semantically transparent to 'novice users'?

- RQ2: How does the previous knowledge impacts the comprehension of process landscape designs?

Accordingly, the paper is organized as follows. The introduction chapter already identified the problem and motivation for the research, whereas the second chapter contains background on process landscapes, semiotics, and semantic transparency. The third chapter introduces empirical research, which was applied to provide answers to the stated research questions. The fourth chapter presents and discusses the results of our research. The last chapter brings conclusions and limitations of our approach as well as implications and future research directions.

\section{Research Background}

\subsection{Process Landscapes}

A high-level model of an organization that represents an overall structure of business processes and their relationships, emerged as a tool to aid process-oriented companies in managing large business process collections [10]. With roots in the early 1980s, 
when Porter [11] introduced the value chain model, the concept is commonly specified as a 'process landscape' and represents a set of interconnected processes within an organizational system. Alternative terms in use are 'process overview' [12], and 'process map'. However, according to the findings of Poels et al. [13], the term 'process map' may either represent a model of a business process architecture or an entry-level model of a business process model architecture.

A process landscape model (Fig. 1) shows the structure, grouping, modularity, functionality, and technology of chain processes, business processes, and working processes. In contrast to business process models, processes on the landscape level are modeled as 'black-boxes' whose internal complexity is hidden for the sake of simplicity and clarity.
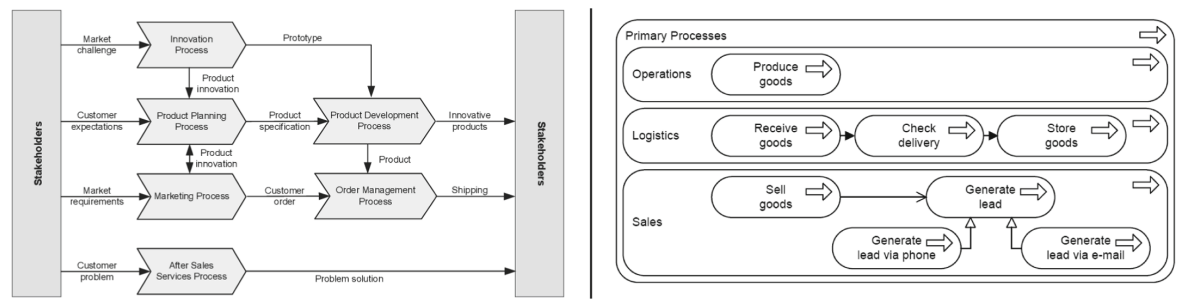

Fig. 1. Examples of process landscape diagrams $[15,16]$

Process landscape diagrams may be used in numerous ways, addressing the concerns of business-oriented users as well as technically-oriented ones [12]. While being specified on the macro level, they provide a comprehensive understanding and highlight different types of relationships or dependencies with other processes and artifacts [14]. Process landscape diagrams help process owners, quality managers, and other process-related stakeholders to ease the maintenance of their processes by offering a quick overview of processes. Afterward, in detailed process diagrams, individual business processes may be decomposed into finer levels of detail (i.e., sub-processes and tasks). In summary, like modeling individual processes is a starting point for any process improvement effort, modeling the architecture of an organization's collection of business processes is required for any analysis, design or improvement effort that transcends the level of individual processes [13].

Figure 1 represents two common process landscape diagrams, with processes depicted as chevron arrows (left) or rectangles (right), whereas arrows represent betweenprocess relationships. The left diagram in Fig. 1 additionally connects organizational processes with the environment by specifying connections to external participants (i.e., stakeholders).

\subsection{Modeling Process Landscapes with BPMN 2.0}

The evidence from academia and practice show that BPMN is used for modeling of process landscapes in an informal way [17, 18]. In our previous work [18], three different BPMN-based approaches for modeling of process landscaped have been investigated: (1) use of black-box Pools and Message flows for modeling of BPMN Collaboration 
diagrams with hidden details; (2) use of BPMN Collaboration diagrams and (3) use of Enterprise-wide BPMN Process diagrams.

An analysis performed in [18] demonstrates that none of the BPMN approaches results in diagrams with a graphical similarity to common landscape diagrams (e.g., value chains). Analytically, this was confirmed by Malinova et al. [19], who performed a semantical mapping between BPMN and 'Process maps'. Their results show that $\mathrm{BPMN}$ in its current form is not appropriate for process landscape design.

\subsection{Semiotics}

The theoretical foundation on how a visual vocabulary of a notation is defined can be explained by semiotics [20], i.e. a study of signs, an investigation into how the meaning is created and communicated. According to semiotics, a sign consists of a signifier (i.e. any material thing that is signified, be it an object, words on a page, or an image) and signified (i.e. the concept which the signifier refers to) (Fig. 2, left).
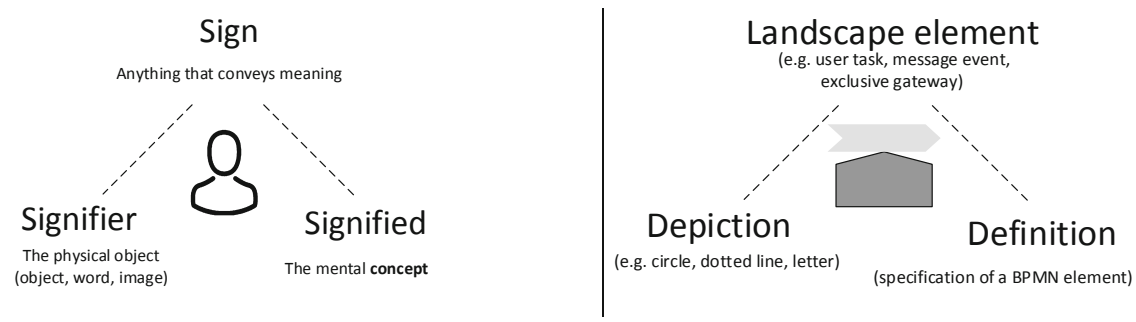

Fig. 2. Main concepts as specified in semiotics (left) and OMG's namespace (right)

Based on the relation between the signifier and signified, semiotics defines three types of signs: (1) icon, where a signifier physically resembles the signified (i.e. person sign on Fig. 2); (2) symbol, where the signifier presents the signified with an arbitrary or conventional relation; and (3) index, where the signifier is related to the signified by an associative relation (i.e. Fig. 2, right - the darker symbol supports the lighter one (from below), which is analogous to common real-life situations). In the process languages' space (e.g. BPMN, CMMN, DMN), a sign is commonly referred to as an element, whereas the signifier is commonly referred to as a depiction of an element [21]. The definition of a process element has an equal meaning as a 'signified' in semiotics, meaning the specification of a language concept. Since the focus of our investigation is on process languages, we will use the terms according to the process languages namespace, i.e. a 'process element consists of its definition and depiction'.

\subsection{Semantic Transparency}

Caire et al. [22] stated that "The key to designing visual notations that are understandable to nä̈ve users is a property called semantic transparency", which means that the meaning (semantics) of a sign is clear (i.e. intuitive, transparent) from its appearance alone 
(as in the case of onomatopoeia in spoken languages). Therefore, addressing semantic transparency is recognized as one of the most powerful approaches for improving the understandability, especially for novice users [22].

Semantic transparency of a sign is a continuous function with two endpoints. On the positive side, a sign may be semantic transparent, which means that a novice reader could accurately deduce the meaning of a sign from its appearance (e.g., a drawn tree representing a tree). Semantically transparent signs tend to be defined either by similarity or an associative relationship (index). In contrast, semantic perversity means that a novice reader would likely deduct an incorrect meaning from the sign's appearance (e.g., an arrow directed in an opposite way to an actual flow). On the midpoint, a sign may be defined as semantically opaque, which means that it is defined by a convention [22]. Semantically transparent signs reduce cognitive load because they have built-in mnemonics: as a result, their meaning can be either perceived directly or easily learned [23]. Such representations speed up recognition and improve intelligibility to naïve users [24, 25]. Indeed, one of the main challenges of modeling languages is to model the diagram in a precise and user-friendly way, where each applied graphical element should be intuitive for users [26], which positively implies the acceptance of a modeling technique [27].

\section{Empirical Research}

\subsection{Research Model and Process}

In respect to $R Q 1$, we identified two independent variables, namely 'depiction of a landscape concept' and 'contextual information'. In the case of the former, we searched for the levels of the independent variable among the various sources of process landscape diagrams whereas the visual vocabularies of the corresponding notations have been identified (i.e. levels represented common landscape symbols). The 'contextual information' variable was additionally introduced, since the meaning of an individual element may be more precisely identified when putting it into the context (element level and diagram level). The dependent variable was defined as 'semantic transparency', which represents the extent to which the meaning of a symbol can be inferred from its appearance. We operationalized the 'semantic transparency' as the number of correctly identified meanings of the investigated elements, i.e. comprehension. Higher values were preferred, representing semantic immediate symbols (i.e. a novice reader can infer the meaning from its appearance alone).

In respect to $R Q 2$, two types of previous knowledge (i.e. expertise) have been considered as independent variables: 'BPMN expertise' and 'Landscape modeling expertise'. 'BPMN expertise' was considered since BPMN represents ISO and the de-facto standard for process modeling, where some attempts in academia and practice actually apply BPMN for landscape modeling [28]. Accordingly, we presume that BPMN expertise may impact the subjects on how they perceive landscape elements. In a similar manner, 'Landscape modeling expertise' may impact the subjects' answers. In both cases, the 'expertise' was investigated on a 7-point Likert scale from highest to lowest degree of disagreement, with items adapted from Recker [29]. 
To provide answers to the stated research questions, we performed empirical research as follows. To test to what extent 'novice users' would be likely to infer the correct meaning for the common landscape designs, subjects were introduced with different landscape elements and (partial) diagrams, where their task was to identify the meaning for the provided depictions. The applied research protocol may correspond to preexperimental designs, more specifically 'one group posttest only design' [30]. In our case, the treatments were associated with the instructions, provided to subjects, whereas the observations are associated with the subject's responses.

\subsection{Subjects and Sampling}

Since we investigated intuitiveness, the ideal candidate for the research would be an individual who (1) understands the meaning of the concepts, which are used in landscape modeling, yet has (2) no experiences with the corresponding landscape modeling notations. According to this, IT and business students of the same degree were selected as suitable candidates for the research.

\subsection{Research Instrument}

The focal research instrument was an online questionnaire, which was categorized into the following parts. In the first part, subjects were asked to provide basic demographic information (age, gender), and their experiences in BPMN as well as in landscape modeling (both measured on a 7-point Likert scale from lowest to the highest degree of experience, and self-reported number of modeled diagrams). In the second part, subjects were introduced by alternative depictions of common landscape elements (i.e. landscape elements as used in academia and industry, including BPMN and Archimate), where they were asked to associate the most appropriate meaning to them (including the 'undecided' answer). In addition, partial diagrams were presented to subjects to test if they would more effectively infer the meaning if using a diagram's contextual information. To minimize learning effects, the individual items as well the answers were randomized. In the third part of the questionnaire, a "two-treatments" alike design was applied to test the alternative notations used in landscaped modeling. Due to the paper's length limitations, this part was excluded from this paper. The instrument was prepared in Slovenian and English version and was completely anonymized. The actual research was performed in January 2019. In total, 588 subjects were invited to participate, 347 subjects actually opened the questionnaire or partially completed it, whereas 302 subjects successfully completed the questionnaire. Out of them, $65 \%$ of the subject came from Slovenia, whereas $35 \%$ came from Ukraine.

\section{Results}

The results were collected and partially analyzed in 1KA (https://www.1ka.si/d/en), an advanced open-source application that enables services for online surveys. Afterward, the data was exported into MS Excel as well as SPSS, to perform additional analysis. 


\subsection{Descriptive Statistics}

As previously mentioned, 302 subjects successfully completed the questionnaire, 161 of them male (53\%) and 141 female (47\%). In average subjects were 21.3 years old when completing the questionnaire. 197 subjects $(65 \%)$ come from Slovenia, whereas 105 subjects (35\%) came from Ukraine and so completed the survey in the English language. On average, it took eight minutes and four seconds to complete the questionnaire. Based on subjects' expertise with BPMN and landscapes modeling, subjects were classified into the following levels of expertise (Table 1): (1) inexperienced - the subjects who partially or fully disagreed on having any experience in BPMN or landscapes modeling (in all Likert items); (2) BPMN experts - subjects who partially to fully agreed on having expertise in BPMN (in all Likert items); (3) landscape modeling experts - subjects who partially to fully agreed on having expertise in landscape modeling (in all Likert items).

Table 1. Descriptive statistics with respect to subjects' expertise

\begin{tabular}{l|c|c|c|c|c|r}
\hline Expertise & Male & Female & Slovenia & Ukraine & Total & T. [\%] \\
\hline Inexperienced & 80 & 68 & 102 & 46 & 148 & $49 \%$ \\
\hline BPMN expertise & 34 & 18 & 44 & 8 & 52 & $17 \%$ \\
\hline Landscape modeling expertise & 7 & 9 & 10 & 6 & 16 & $5 \%$ \\
\hline All & 161 & 141 & 197 & 105 & 302 & $100 \%$ \\
\hline
\end{tabular}

As evident from Table 1, the sum of all levels of expertise does not match all subjects, since those subjects who specified 'undecided' on their level of expertise were not classified into any level of expertise.

\subsection{Comprehension of Process Landscape Elements}

In order to investigate the comprehension of the depictions of common landscape elements, subjects were asked to associate the correct meaning to the stated symbols, where they had an additional 'undecided' option to answer. In total 291 subjects completely answered this question, choosing 'undecided' at an average of $25 \%$ of the answers. Table 2 summarizes these results by showing the percentage of answers associated with individual definitions. We bolded the highest (preferred) values for individual depictions and highlighted (in the gray background) the correct definitions (i.e. as specified or use $\mathrm{d}$ in praxis). As evident from Table 2, subjects associated the symbols to the correct definitions, consistently and at all levels of expertise in the cases of all process elements (depictions D1, D2, D3, and D5) as well in the cases of 'data elements' (depictions D8, and D9). In the remaining cases, the associations of definitions of the stated symbols depend on the level of expertise as follows. The rectangle (D4) was recognized either as a process or as a participant, which may have roots in BPMN's specification of the concept of a Pool. A BPMN Pool may either be treated as a participant or as a process in case it references one. 
Table 2. Comprehension of landscape elements

\begin{tabular}{|c|c|c|c|c|c|c|c|c|c|c|c|c|c|c|c|}
\hline 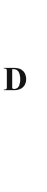 & land & 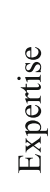 & 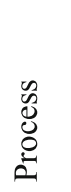 & 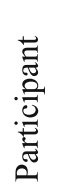 & $\begin{array}{l}\dot{0} \\
\dot{a} \\
\dot{2} \\
\stackrel{2}{\Xi} \\
\dot{n}\end{array}$ & $\begin{array}{l}0 \\
\stackrel{D}{0} \\
\stackrel{\infty}{\infty} \\
\sum^{\infty}\end{array}$ & 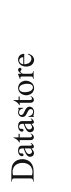 & 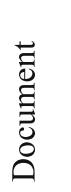 & $\begin{array}{l}\overrightarrow{0} \\
\stackrel{0}{0} \\
0 \\
0 \\
\dot{0} \\
\dot{0}\end{array}$ & 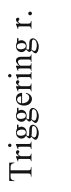 & 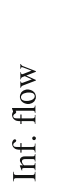 & 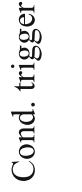 & $\begin{array}{l}\text { - } \\
\dot{0} \\
0 \\
0 \\
1 \\
1 \\
0 \\
0 \\
0\end{array}$ & 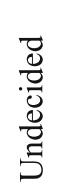 & $\frac{\pi}{\stackrel{D}{\pi}}$ \\
\hline & & $x$ & $29 \%$ & $3 \%$ & $1 \%$ & $6 \%$ & $3 \%$ & $0 \%$ & $3 \%$ & $5 \%$ & $7 \%$ & $4 \%$ & $\%$ & 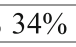 & 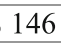 \\
\hline & & B & $39 \%$ & $4 \%$ & $2 \%$ & $10 \%$ & $0 \%$ & $0 \%$ & $6 \%$ & $2 \%$ & $8 \%$ & $2 \%$ & 78 & & {$[-$} \\
\hline & & $\mathrm{L}$ & $31 \%$ & $0 \%$ & $6 \%$ & $19 \%$ & $0 \%$ & $0 \%$ & $6 \%$ & $6 \%$ & $6 \%$ & $0 \%$ & $0 \%$ & & 16 \\
\hline & & $\bar{A}$ & $32 \%$ & $4 \%$ & $3 \%$ & $8 \%$ & $2 \%$ & $0 \%$ & $3 \%$ & $4 \%$ & $8 \%$ & $3 \%$ & $3 \%$ & & 291 \\
\hline \multirow{4}{*}{2} & & I & $18 \%$ & $6 \%$ & $8 \%$ & $10 \%$ & $3 \%$ & $1 \%$ & $4 \%$ & $2 \%$ & $3 \%$ & $5 \%$ & $\%$ & & 146 \\
\hline & & B & $25 \%$ & $4 \%$ & $8 \%$ & $8 \%$ & $2 \%$ & $0 \%$ & $2 \%$ & $0 \%$ & $2 \%$ & $8 \%$ & $4 \%$ & & 51 \\
\hline & & L & $25 \%$ & $6 \%$ & $19 \%$ & $0 \%$ & $0 \%$ & $0 \%$ & $0 \%$ & $0 \%$ & $0 \%$ & $0 \%$ & $6 \%$ & & 16 \\
\hline & & A & $16 \%$ & $5 \%$ & $8 \%$ & $10 \%$ & $4 \%$ & $1 \%$ & $3 \%$ & $2 \%$ & $4 \%$ & $8 \%$ & $4 \%$ & & 291 \\
\hline \multirow{4}{*}{3} & & I & $5 \%$ & $11 \%$ & $12 \%$ & $10 \%$ & $3 \%$ & $1 \%$ & $3 \%$ & 10 & $3 \%$ & $4 \%$ & $2 \%$ & & 146 \\
\hline & & B & $4 \%$ & $4 \%$ & $29 \%$ & $10 \%$ & $0 \%$ & $2 \%$ & $0 \%$ & $0 \%$ & $2 \%$ & $\%$ & $\%$ & & 51 \\
\hline & & $\mathrm{L}$ & $6 \%$ & $6 \%$ & $19 \%$ & $6 \%$ & $0 \%$ & $0 \%$ & $0 \%$ & $0 \%$ & $0 \%$ & $6 \%$ & $6 \%$ & & 16 \\
\hline & & A & $5 \%$ & $11 \%$ & $17 \%$ & $9 \%$ & $4 \%$ & $2 \%$ & $2 \%$ & $1 \%$ & $2 \%$ & $5 \%$ & $2 \%$ & & 291 \\
\hline & & I & $9 \%$ & $27 \%$ & $1 \%$ & $1 \%$ & $12 \%$ & $6 \%$ & $1 \%$ & $0 \%$ & $1 \%$ & $2 \%$ & $1 \%$ & & 146 \\
\hline & & $\mathrm{B}$ & $41 \%$ & $20 \%$ & $2 \%$ & $6 \%$ & $2 \%$ & $2 \%$ & $0 \%$ & $0 \%$ & $0 \%$ & $0 \%$ & $2 \%$ & & 51 \\
\hline & & $\mathrm{L}$ & $44 \%$ & $19 \%$ & $0 \%$ & $13 \%$ & $0 \%$ & $6 \%$ & $0 \%$ & $6^{\circ}$ & $0 \%$ & $0 \%$ & $6 \%$ & $\%$ & 16 \\
\hline & & A & $19 \%$ & $24 \%$ & $1 \%$ & $3 \%$ & $10 \%$ & $5 \%$ & $1 \%$ & 0 & 0 & $\%$ & 0 & & 291 \\
\hline & & I & $3 \%$ & $8 \%$ & $12 \%$ & $12 \%$ & $2 \%$ & $3 \%$ & $2 \%$ & $3 \%$ & $3 \%$ & $\%$ & $1 \%$ & & 146 \\
\hline & & B & $2 \%$ & $0 \%$ & $18 \%$ & $25 \%$ & $0 \%$ & $2 \%$ & $0 \%$ & $2 \%$ & $2 \%$ & $2 \%$ & $2 \%$ & & 51 \\
\hline & & $\mathrm{I}$ & $0 \%$ & $0 \%$ & $13 \%$ & $25 \%$ & $6 \%$ & $0 \%$ & $0 \%$ & $6 \%$ & $6 \%$ & $0 \%$ & $6 \%$ & & 16 \\
\hline & & $\overline{\mathrm{A}}$ & $3 \%$ & $6 \%$ & $12 \%$ & $14 \%$ & $3 \%$ & $3 \%$ & $3 \%$ & - & $3 \%$ & $3 \%$ & $\%$ & & 291 \\
\hline & & $\mathrm{I}$ & $8 \%$ & $7 \%$ & $18 \%$ & $5 \%$ & $3 \%$ & $1 \%$ & $5 \%$ & & $3 \%$ & $\%$ & $5 \%$ & & 146 \\
\hline & & B & $8 \%$ & $0 \%$ & $16 \%$ & $12 \%$ & $0 \%$ & $0 \%$ & $22 \%$ & & $2 \%$ & $8 \%$ & $6 \%$ & & 51 \\
\hline & & L & $0 \%$ & $0 \%$ & $25 \%$ & $6 \%$ & $6 \%$ & $0 \%$ & $13 \%$ & 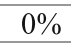 & $6 \%$ & $6 \%$ & & & 16 \\
\hline & & A & $7 \%$ & $4 \%$ & $\%$ & $6 \%$ & $3 \%$ & $1 \%$ & $9 \%$ & $3 \%$ & $3 \%$ & $7 \%$ & $6 \%$ & & 291 \\
\hline & & I & $3 \%$ & $5 \%$ & $1 \%$ & $1 \%$ & $59 \%$ & $1 \%$ & $8 \%$ & $3 \%$ & $1 \%$ & $2 \%$ & $1 \%$ & $16 \%$ & 146 \\
\hline & & B & $2 \%$ & $2 \%$ & $0 \%$ & $0 \%$ & $88 \%$ & $0 \%$ & $2 \%$ & $0 \%$ & $0 \%$ & $0 \%$ & $0 \%$ & $6 \%$ & \\
\hline & & $\mathrm{L}$ & $0 \%$ & $6 \%$ & $0 \%$ & $0 \%$ & $69 \%$ & $0 \%$ & $19 \%$ & $0 \%$ & $0 \%$ & $0 \%$ & $0 \%$ & $6 \%$ & 16 \\
\hline & & $\Delta$ & $2 \%$ & $7 \%$ & $1 \%$ & $1 \%$ & $58 \%$ & $1 \%$ & $9 \%$ & 2 & $1 \%$ & $2 \%$ & $1 \%$ & $16 \%$ & 291 \\
\hline & & I & $1 \%$ & $1 \%$ & $1 \%$ & $1 \%$ & $2 \%$ & $85 \%$ & $1 \%$ & $0 \%$ & $1 \%$ & $1 \%$ & $0 \%$ & $\%$ & 146 \\
\hline & & B & $0 \%$ & $0 \%$ & $0 \%$ & $2 \%$ & $6 \%$ & $92 \%$ & $\%$ & $0 \%$ & $0 \%$ & $0 \%$ & $0 \%$ & $0 \%$ & \\
\hline & & $\mathrm{L}$ & $0 \%$ & $0 \%$ & $0 \%$ & $0 \%$ & $13 \%$ & $88 \%$ & $0 \%$ & $0 \%$ & $0 \%$ & $0 \%$ & $0 \%$ & $0 \%$ & 16 \\
\hline & & $\overline{\mathrm{A}}$ & $1 \%$ & $0 \%$ & $0 \%$ & $1 \%$ & $3 \%$ & $88 \%$ & $1 \%$ & $0 \%$ & $1 \%$ & $0 \%$ & $0 \%$ & $5 \%$ & 291 \\
\hline & 2 & 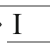 & $18 \%$ & $0 \%$ & $3 \%$ & $5 \%$ & $1 \%$ & & $1 \%$ & $14 \%$ & $32 \%$ & $3 \%$ & $6 \%$ & $17 \%$ & 146 \\
\hline & & $\mathrm{B}$ & $4 \%$ & $2 \%$ & $0 \%$ & $0 \%$ & $2 \%$ & $0^{\circ}$ & $2 \%$ & $\%$ & $25 \%$ & $4 \%$ & $2 \%$ & $4 \%$ & 51 \\
\hline & & $\mathrm{L}$ & & $6^{\circ}$ & $6 \%$ & $0 \%$ & & & $\%$ & 31 & $\%$ & $0 \%$ & $0 \%$ & $\%$ & 16 \\
\hline & & A & $15 \%$ & $1 \%$ & $2 \%$ & $5 \%$ & $1 \%$ & 10 & $1 \%$ & $22 \%$ & $30 \%$ & $3 \%$ & $7 \%$ & 0 & 291 \\
\hline \multirow{4}{*}{10} & & I & $6 \%$ & $1 \%$ & $3 \%$ & $4 \%$ & $0 \%$ & $0 \%$ & $4 \%$ & $13 \%$ & $15 \%$ & $10 \%$ & $16 \%$ & $27 \%$ & 146 \\
\hline & & B & $6 \%$ & $0 \%$ & $4 \%$ & $2 \%$ & $0 \%$ & $0 \%$ & $2 \%$ & $10 \%$ & $4 \%$ & $31 \% 2$ & $24 \%$ & $18 \%$ & 51 \\
\hline & & $\mathrm{L}$ & $6 \%$ & $0 \%$ & $0 \%$ & $6 \%$ & $0 \%$ & $0 \%$ & $0 \%$ & $19 \%$ & $25 \%$ & $25 \%$ & $6 \%$ & $13 \%$ & 16 \\
\hline & & $\bar{A}$ & $7 \%$ & $1 \%$ & $4 \%$ & $4 \%$ & $1 \%$ & $0 \%$ & $3 \%$ & $12 \%$ & & & $7 \%$ & $24 \%$ & 291 \\
\hline
\end{tabular}

Expertise: $I=$ inexperienced; $B=B P M N$ expert; $L=$ landscapes modeling expert; $A=$ all subjects. 
The symbol for the collapsed processes collection (D6) was correctly identified by BPMN experts, which may have roots in an analogous representation of a collapsed BPMN subprocess. Expanded collections of processes (D9 and D10) haven't been identified correctly. However, this may have roots in the research instrument since subjects focused on the relationships between processes present on the collection instead of the collection itself.

Individual landscape elements, as well as the relationships between them, were additionally investigated by considering contextual information, i.e. by putting elements into (partial diagrams). Initially, subjects were asked to identify the type of process by providing them a simple value chain-based landscape diagram (Fig. 3).

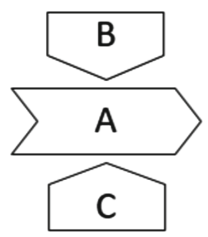

Fig. 3. Common depictions of process types in a value chain model

In this case, subjects recognized the core process correctly in $73 \%$, whereas the supporting process was recognized correctly by $68 \%$ of subjects. This is a significant increase when compared to the individually investigated symbols (17\%, Table 2, D3). In the case of the management process, the success rate was $59 \%$, whereas in the individual investigation it was $14 \%$ (Table 2, D5).

\subsection{Comprehension of Between-Processes Relationships}

The explicit relationships between processes in a process landscape diagram were investigated individually and by providing subjects the following two diagrams (Fig. 4).
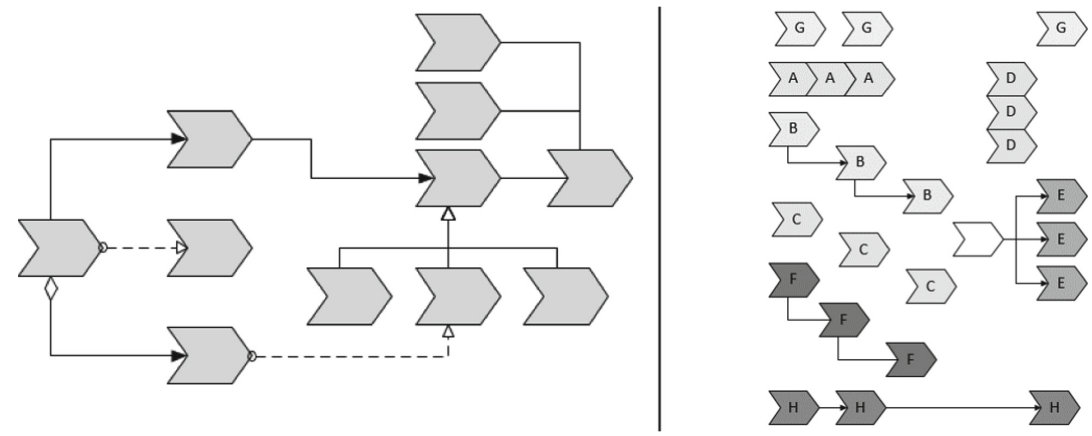

Fig. 4. Investigation of relationships between processes (part 1, left; part 2, right) 
The focus of the left diagram in Fig. 4 was to investigate the relationships between processes as specified by Eid Sabbagh et al. [31], namely composition, specialization, trigger, and information flow, with the last two being specified as behavioral ones (Table 3, the highest values are bolded). While two symbols may share the same meaning in praxis which stands for 'symbol overload' (e.g. solid line and arrow, different types of arrows), we did specify any correct definitions in this case.

Table 3. Comprehension of explicit relationships

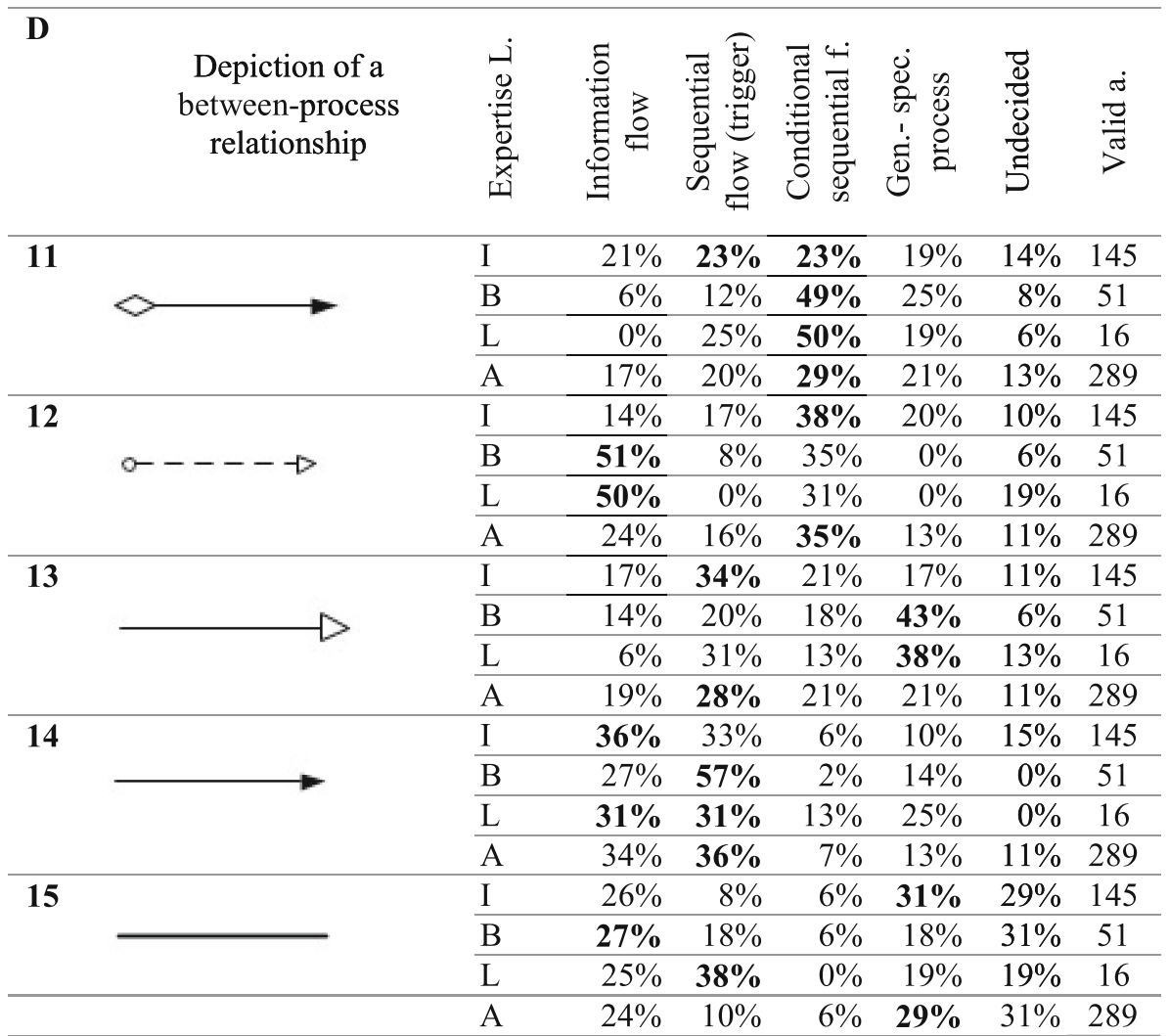

Expertise: $I=$ inexperienced; $B=B P M N$ expert; $L=$ landscapes modeling expert; $A=$ all subjects.

Table 3 reveals that subjects responded the most consistently (in respect to different levels of expertise) in the case of a conditional trigger relationship (D11), which may be associated with the intuitiveness of a diamond shape symbol, commonly representing a decision-point. Information flow (D12) was correctly recognized by experts, which may be related to the fact that the depiction is equal to BPMN's message flow. In a similar manner, the 'generic-specific' relationship (D13) was correctly identified by the experts, who may have the knowledge either of UML class diagrams or Archimate. The sequential relationship (D14) was not correctly recognized by inexperienced users, whereas all other 
expertise levels including all answers inferred the correct meaning. The answers were also inconsistent in the case of a solid line, whereas the majority of subjects reported as being a 'generic-specific' relationship (i.e. as common in organizational charts).

The focus of the right diagram in Fig. 4 was to investigate the implicit relationships between processes, which commonly occur on a landscape diagram, especially valuechain based. In this manner, subjects were asked to specify the relationships between the processes sharing the same letter and color (Table 4).

Table 4. Comprehension of explicit and implicit relationships

\begin{tabular}{|c|c|c|c|c|c|c|c|c|c|c|c|c|}
\hline 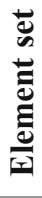 & & 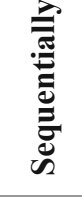 & 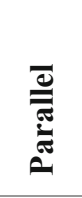 & 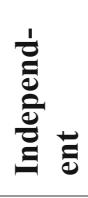 & 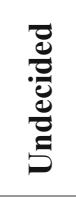 & $\begin{array}{l}\overline{.} \\
\overline{7} \\
\frac{5}{7}\end{array}$ & 总 & 尝 & 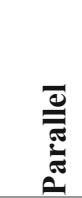 & 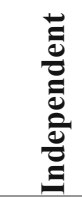 & 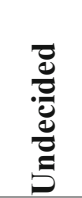 & $\frac{\pi}{\pi}$ \\
\hline \multirow{4}{*}{$\mathbf{A}$} & I & $72 \%$ & $17 \%$ & $1 \%$ & $9 \%$ & 144 & \multirow{4}{*}{$\mathbf{E}$} & $9 \%$ & $61 \%$ & $16 \%$ & $14 \%$ & 144 \\
\hline & $\mathrm{B}$ & $82 \%$ & $16 \%$ & $2 \%$ & $0 \%$ & 51 & & $8 \%$ & $75 \%$ & $14 \%$ & $4 \%$ & 51 \\
\hline & $\mathrm{L}$ & $69 \%$ & $31 \%$ & $0 \%$ & $0 \%$ & 16 & & $6 \%$ & $63 \%$ & $19 \%$ & $13 \%$ & 16 \\
\hline & $\mathrm{A}$ & $72 \%$ & $20 \%$ & $2 \%$ & $6 \%$ & 288 & & $10 \%$ & $63 \%$ & $17 \%$ & $11 \%$ & 288 \\
\hline \multirow{4}{*}{ B } & I & $78 \%$ & $6 \%$ & $6 \%$ & $10 \%$ & 144 & \multirow{4}{*}{$\mathbf{F}$} & $65 \%$ & $12 \%$ & $10 \%$ & $13 \%$ & 144 \\
\hline & $\mathrm{B}$ & $82 \%$ & $10 \%$ & $6 \%$ & $2 \%$ & 51 & & $82 \%$ & $8 \%$ & $4 \%$ & $6 \%$ & 51 \\
\hline & $\mathrm{L}$ & $75 \%$ & $13 \%$ & $6 \%$ & $6 \%$ & 16 & & $88 \%$ & $6 \%$ & $0 \%$ & $6 \%$ & 16 \\
\hline & $\mathrm{A}$ & $75 \%$ & $11 \%$ & $6 \%$ & $9 \%$ & 288 & & $66 \%$ & $13 \%$ & $9 \%$ & $11 \%$ & 288 \\
\hline \multirow{4}{*}{ C } & I & $5 \%$ & $4 \%$ & $80 \%$ & $11 \%$ & 144 & \multirow{4}{*}{$\mathbf{G}$} & $11 \%$ & $4 \%$ & $69 \%$ & $16 \%$ & 144 \\
\hline & B & $2 \%$ & $4 \%$ & $92 \%$ & $2 \%$ & 51 & & $14 \%$ & $2 \%$ & $80 \%$ & $4 \%$ & 51 \\
\hline & $\mathrm{L}$ & $6 \%$ & $6 \%$ & $88 \%$ & $0 \%$ & 16 & & $19 \%$ & $6 \%$ & $75 \%$ & $0 \%$ & 16 \\
\hline & $\mathrm{A}$ & $5 \%$ & $5 \%$ & $81 \%$ & $9 \%$ & 288 & & $11 \%$ & $5 \%$ & $72 \%$ & $12 \%$ & 288 \\
\hline \multirow{4}{*}{ D } & I & $8 \%$ & $67 \%$ & $13 \%$ & $11 \%$ & 144 & \multirow{4}{*}{ H } & $77 \%$ & $3 \%$ & $2 \%$ & $17 \%$ & 144 \\
\hline & B & $6 \%$ & $76 \%$ & $16 \%$ & $2 \%$ & 51 & & $94 \%$ & $0 \%$ & $4 \%$ & $2 \%$ & 51 \\
\hline & $\mathrm{L}$ & $0 \%$ & $94 \%$ & $6 \%$ & $0 \%$ & 16 & & $81 \%$ & $0 \%$ & $13 \%$ & $6 \%$ & 16 \\
\hline & $\mathrm{A}$ & $7 \%$ & $73 \%$ & $12 \%$ & $8 \%$ & 288 & & $79 \%$ & $4 \%$ & $4 \%$ & $13 \%$ & 288 \\
\hline
\end{tabular}

As evident from Table 4, subjects responded completely consistently in all sets of related processes (Fig. 4, right) and in all expertise levels. So, we can conclude that they have no problems identifying sequentially, parallel or independent processes either connected explicitly with arrows or implicitly by using the mechanism of proximity.

\section{Conclusions}

Based on the results which were presented and discussed in the previous chapter, we may provide the answers to the stated research questions as follows. 
RQ1: Are common landscape designs semantically transparent to 'novice users'? When observing the subgroup of subjects, who did not report any level of expertise in BPMN and landscapes modeling (Table 1, 'inexperienced'), we may conclude that they were able to successfully associate the stated depictions of process landscape elements to the meanings they share in the diagrams (Table 2), especially in the cases, where symbols share the same meaning over different notations (e.g. D7 and D8 in Table 2). They also successfully recognized all process symbols, especially when considering them in the context, as summarized in Table 5.

Table 5. Process depictions as recognized by inexperienced users

\begin{tabular}{lccc}
\hline Symbol & & & \\
\hline Individual element level & $12 \%$ & $29 \%$ & $12 \%$ \\
\hline Diagram level (context) & $58 \%$ & $72 \%$ & $67 \%$ \\
\hline
\end{tabular}

When comparing the results of alternative process representations (e.g. D1 and D2 in Table 2), subjects reported better in the case of the chevron symbol (D1) despite the fact D2 is used in a formal specification (ArchiMate). In respect to between-process connections, the 'inexperienced' subgroup of subjects failed to associate the stated depictions to the proper meanings as used in landscape diagrams (Table 3), despite the fact that the investigated depictions were put into the context (Fig. 4, left). However, the same subjects reported consistently with experienced users when identifying sequentially, parallel or independent processes either connected explicitly with arrows or implicitly by facilitating the mechanism of proximity between the elements.

RQ2: How does the previous knowledge impacts the comprehension of process landscape designs?

Two types of previous knowledge were investigated in our research: experiences with BPMN and experience with landscape modeling (Table 1). The results of our investigation show that by considering previous knowledge subjects responded differently in several cases when compared to 'inexperienced' subgroup of subjects. These were most evident in the cases of a rectangle (Table 2, D4) and chevron arrow with a plus sign (Table 2, D6). Table 6 summarizes these by comparing the comprehension of process landscape elements by considering their definitions as specified or used in praxis.

Besides, the connection elements, which depictions are mainly specified in a conventional way (they do not have any 'built-in mnemonics') have reported different comprehension levels, when considering different levels of expertise. E.g. in the case of BPMN experts a dotted arrow was successfully associated with an information flow (in BPMN it represents a Message flow), whereas they successfully associated solid arrow with a triggering relationship (in BPMN it represents a Message flow). 
Table 6. Comprehension of landscape elements in respect to levels of expertise

\begin{tabular}{|c|c|c|c|c|c|c|c|c|c|c|c|}
\hline 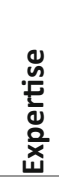 & 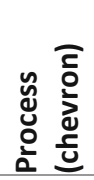 & 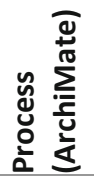 & 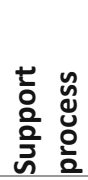 & 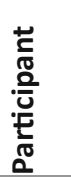 & 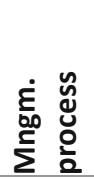 & 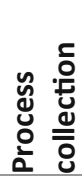 & 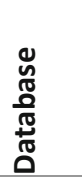 & 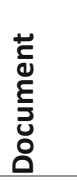 & 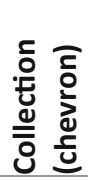 & 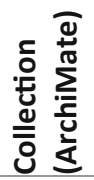 & 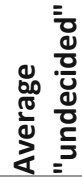 \\
\hline I & $29 \%$ & $18 \%$ & $12 \%$ & $27 \%$ & $12 \%$ & $5 \%$ & $59 \%$ & $85 \%$ & $1 \%$ & $4 \%$ & $27 \%$ \\
\hline $\mathbf{L}$ & $39 \%$ & $25 \%$ & $29 \%$ & $20 \%$ & $25 \%$ & $22 \%$ & $88 \%$ & $92 \%$ & $2 \%$ & $2 \%$ & $21 \%$ \\
\hline B & $31 \%$ & $25 \%$ & $19 \%$ & $19 \%$ & $25 \%$ & $13 \%$ & $69 \%$ & $88 \%$ & $6 \%$ & $0 \%$ & $21 \%$ \\
\hline
\end{tabular}

\subsection{Implications}

We foresee several implications of our investigation. First, experts involved in developing and evolving process landscape languages may consider our research results to select and/or specify the depictions of elements which are intuitive to modelers. Secondly, the selection of visual elements for process landscape design should consider related notations (e.g. BPMN), where elements depictions may already have standardized meanings and therefore should not be overridden. Our research may also be of use for researchers who investigate and propose simplifications of complex process languages, as well as for the ones who extend existing visual languages.

\subsection{Research Limitations and Future Work}

The results of this research should be considered with the following internal and external limitations in mind. With respect to the external validity, there is a certain degree of risk of generalizing results above the research sample. While students reported as not being skilled in BPMN and landscape modeling languages, another group of subjects could provide different results (e.g. subjects from another environment could be impacted by other signs in their everyday life). Besides, the sample of subjects experienced in landscape design was rather small (16 subjects). Secondly, there is also a certain degree of risk associated with the instrument, where the subject may not be able to correctly interpret the depictions as well the semantics of the symbols out of the instructions (e.g. as in the case of expanded process collections).

Our future work will be focused on specifying a modified landscape modeling notation, based on these results and test if the resulting diagrams are more cognitively effective when compared to existing ones. Besides, we may extend the research to other regions to test on how cultural differences may impact the intuitiveness of symbols.

Acknowledgment. The authors (Gregor Polančič) acknowledge the financial support from the Slovenian Research Agency (research core funding No. P2-0057). 


\section{References}

1. Dijkman, R., Vanderfeesten, I., Reijers, H.A.: Business process architectures: overview, comparison and framework. Enterp. Inf. Syst. 10, 129-158 (2016). https://doi.org/10.1080/ 17517575.2014.928951

2. Dumas, M., Rosa, M.L., Mendling, J., Reijers, H.: Fundamentals of Business Process Management. Springer, Heidelberg (2018). https://doi.org/10.1007/978-3-662-56509-4

3. Becker, J., Pfeiffer, D., Räckers, M., Fuchs, P.: Business process management in public administrations-the PICTRUE approach. In: PACIS 2007 Proceedings, p. 142 (2007)

4. Malinova, M., Leopold, H., Mendling, J.: An explorative study for process map design. In: Nurcan, S., Pimenidis, E. (eds.) CAiSE Forum 2014. LNBIP, vol. 204, pp. 36-51. Springer, Cham (2015). https://doi.org/10.1007/978-3-319-19270-3_3

5. Van Nuffel, D., De Backer, M.: Multi-abstraction layered business process modeling. Comput. Ind. 63, 131-147 (2012). https://doi.org/10.1016/j.compind.2011.12.001

6. von Rosing, M., von Scheel, H., Scheer, A.-W.: The Complete Business Process Handbook: Body of Knowledge from Process Modeling to BPM, Volume I: Body of Knowledge from Process Modeling to BPM, vol. 1. Morgan Kaufmann, Waltham (2014)

7. Larkin, J.H., Simon, H.A.: Why a diagram is (sometimes) worth ten thousand words. Cogn. Sci. 11, 65-100 (1987)

8. Siau, K.: Informational and computational equivalence in comparing information modeling methods. JDM 15, 73-86 (2004). https://doi.org/10.4018/jdm.2004010103

9. Zhang, J., Norman, D.: Representations in distributed cognitive tasks. Cogn. Sci. 18, 87-122 (1994)

10. Gonzalez-Lopez, F., Bustos, G.: Business process architecture design methodologies - a literature review. Bus. Process Manag. J. (2019). https://doi.org/10.1108/BPMJ-09-20170258

11. Porter, M.E.: Competitive Advantage: Creating and Sustaining Superior Performance. Free Press; Collier Macmillan, New York, London (1985)

12. Gonzalez-Lopez, F., Pufahl, L.: A landscape for case models. In: Reinhartz-Berger, I., Zdravkovic, J., Gulden, J., Schmidt, R. (eds.) BPMDS/EMMSAD -2019. LNBIP, vol. 352, pp. 87-102. Springer, Cham (2019). https://doi.org/10.1007/978-3-030-20618-5_6

13. Poels, G., García, F., Ruiz, F., Piattini, M.: Architecting business process maps. Comput. Sci. Inf. Systems. (2019). https://doi.org/10.2298/csis181118018p

14. Stefanov, V., List, B., Schiefer, J.: Bridging the gap between data warehouses and business processes: a business intelligence perspective for event-driven process chains. In: Ninth IEEE International EDOC Enterprise Computing Conference, EDOC 2005, pp. 3-14. IEEE (2005)

15. Weske, M.: Business Process Management: Concepts, Languages, Architectures. Springer, Heidelberg (2019)

16. Dijkman, R., Vanderfeesten, I., Reijers, H.A.: The Road to a Business Process Architecture: An Overview of Approaches and Their Use. Einhoven University of Technology, The Netherlands (2011)

17. Muehlen, M.Z., Ho, D.T.: Service process innovation: a case study of BPMN in practice. In: Hawaii International Conference on System Sciences, Proceedings of the 41st Annual. p. 372 (2008). https://doi.org/10.1109/HICSS.2008.388

18. Polančič, G., Huber, J., Tabares, M.S.: An analysis of BPMN-based approaches for process landscape design [Elektronski vir]. Presented at the Gregor Polančič, Jernej Huber, Marta S. Tabares (2017)

19. Malinova, M., Mendling, J.: Why is BPMN not appropriate for Process Maps? In: ICIS 2015 Proceedings. (2015)

20. Chandler, D.: Semiotics: The Basics. Routledge, London; New York (2007) 
21. OMG: Business Process Model and Notation version 2.0, http://www.omg.org/spec/BPMN/ 2.0/. Accessed 15 Mar 2011

22. Caire, P., Genon, N., Heymans, P., Moody, D.L.: Visual notation design 2.0: towards user comprehensible requirements engineering notations. In: 2013 21st IEEE International Requirements Engineering Conference (RE), pp. 115-124 (2013). https://doi.org/10.1109/RE.2013. 6636711

23. Petre, M.: Why looking isn't always seeing: readership skills and graphical programming. Commun. ACM 38, 33-44 (1995). https://doi.org/10.1145/203241.203251

24. Britton, C., Jones, S.: The untrained eye: how languages for software specification support understanding in untrained users. Hum.-Comput. Interact. 14, 191-244 (1999). https://doi. org/10.1080/07370024.1999.9667269

25. Britton, C., Jones, S., Kutar, M., Loomes, M., Robinson, B.: Evaluating the intelligibility of diagrammatic languages used in the specification of software. In: Anderson, M., Cheng, P., Haarslev, V. (eds.) Diagrams 2000. LNCS (LNAI), vol. 1889, pp. 376-391. Springer, Heidelberg (2000). https://doi.org/10.1007/3-540-44590-0_32

26. Hruby, P.: Structuring specification of business systems with UML (with an emphasis on workflow management systems). In: Patel, D., Sutherland, J., Miller, J. (eds.) Business Object Design and Implementation II, pp. 77-89. Springer, London (1998). https://doi.org/10.1007/ 978-1-4471-1286-0_9

27. Neiger, D., Churilov, L., Flitman, A.: Business process modelling with EPCs. In: Neiger, D., Churilov, L., Flitman, A. (eds.) Value-Focused Business Process Engineering: A Systems Approach. ISIS, vol. 14, pp. 1-31. Springer, Boston (2009). https://doi.org/10.1007/978-0387-09521-9_5

28. Polančič, G., Šumak, B., Pušnik, M.: A case-based analysis of process modeling for public administration system design. Inf. Model. Knowl. Bases XXXI 321, 92 (2020)

29. Recker, J.: Continued use of process modeling grammars: the impact of individual difference factors. Eur. J. Inf. Syst. 19, 76-92 (2010)

30. Christensen, L.B., Johnson, B., Turner, L.A., Christensen, L.B.: Research methods, design, and analysis (2011)

31. Eid-Sabbagh, R.-H., Dijkman, R., Weske, M.: Business process architecture: use and correctness. In: Barros, A., Gal, A., Kindler, E. (eds.) BPM 2012. LNCS, vol. 7481, pp. 65-81. Springer, Heidelberg (2012). https://doi.org/10.1007/978-3-642-32885-5_5 